\title{
Circular Economy and Virtual Reality in Advanced BIM-Based Prefabricated Construction
}

\author{
Timothy M. O'Grady 1,2,*(D), Nicholas Brajkovich ${ }^{2}$, Roberto Minunno ${ }^{1,2}$ D, Heap-Yih Chong ${ }^{2}$ \\ and Gregory M. Morrison 1,2
}

1 Curtin University Sustainable Policy (CUSP) Institute, Curtin University, Kent Street, Bentley 6102, Australia; roberto.minunno@curtin.edu.au (R.M.); greg.morrison@curtin.edu.au (G.M.M.)

2 School of Design and the Built Environment, Curtin University, Kent Street, Bentley 6102, Australia; nicholas.brajkovich@postgrad.curtin.edu.au (N.B.); heap-yih.chong@curtin.edu.au (H.-Y.C.)

* Correspondence: timothy.ogrady@postgrad.curtin.edu.au

check for updates

Citation: O'Grady, T.M.; Brajkovich, N.; Minunno, R.; Chong, H.-Y.; Morrison, G.M. Circular Economy and Virtual Reality in Advanced BIM-Based Prefabricated

Construction. Energies 2021, 14, 4065. https://doi.org/10.3390/en14134065

Academic Editor: Peter Luscuere

Received: 5 June 2021

Accepted: 29 June 2021

Published: 5 July 2021

Publisher's Note: MDPI stays neutral with regard to jurisdictional claims in published maps and institutional affiliations.

Copyright: (c) 2021 by the authors. Licensee MDPI, Basel, Switzerland. This article is an open access article distributed under the terms and conditions of the Creative Commons Attribution (CC BY) license (https:// creativecommons.org/licenses/by/ $4.0 /)$.

\begin{abstract}
This paper presents a new virtual reality (VR)-based approach to advanced learnings and experiences of the circular economy (CE) in the construction industry. The approach involves incorporating game design and a building information modelling (BIM) digital twin of a purposed CE prototype building. Our novel approach introduces VR environments designed to provide a visual representation of materials and components that can be reintroduced into the supply chain at the end of life and their removal procedures and material provenance. A case study methodology was applied to a purposely designed CE building, namely the Legacy Living Lab (L3). To reflect the real-life building, L3's BIM model was combined with Unify game software to advance the literature in three key areas. First, the research investigates VR tools that will allow building designers to view and implement their strategies to advance CE design. Second, this research proposes an advanced VR tool to visualise the bill of quantities (BoQ) and material stock embedded in the studied building, further understanding concepts such as buildings as material banks. Finally, the proposed VR environment defines $\mathrm{CE}$ techniques implemented within the case study to be disseminated across the vast construction industry. This VR research identifies three key pillars in reducing the waste generated by the construction industry: education, documentation and visualisation. Furthermore, this paper provides a visual link between the BIM, BoQ and resiliency of the selected materials.
\end{abstract}

Keywords: circular economy; virtual reality; prefabricated construction; BIM

\section{Introduction}

The construction industry stands globally as the largest contributor to waste generation $[1,2]$. The creation of waste is coupled to the high intensity of material consumption, with the industry consuming more than $40 \%$ of all materials produced [3]. These two issues are compounded by a rapidly growing global population and increasing standard of living, leading to a general increase in demolition waste. While building material continues to be disposed of in landfills, growing amounts are being reintroduced to the material loop through recycling [4]. Due to their popularity, materials such as concrete and steel are the predominant focus $[5,6]$, however, concrete and steel recycling processes are not always optimised. Indeed, recycled concrete is often reduced to sand and gravel, a process that diminishes the quality of the initial product-also referred to as downcycling [7]. While recycled steel maintains its original characteristics, that process increases its embodied energy and carbon [8]. To solve the issue of under-optimal recycling processes of building materials, the circular economy (CE) has been suggested as an approach that enables a material transition from the traditional linear business model of take-use-dispose to a model involving the life extension of resources and introducing systems and practices that enable materials to stay in the loop [9]. In terms of construction, a CE system focuses on reducing, reusing, recycling and recovering materials in production, distribution and 
consumption processes [10]. To foster a CE, the closed-loop approach is gaining traction amongst researchers and practitioners as an important guiding principle for the growing construction waste problem [11].

However, there is limited research on wide-scale applications of the CE in construction at the product and component level, with the greater proportion of research based on the end-of-life material recovery options [12]. Typically, at the end of a building's life, there are two main types of demolition processes: conventional and selective $[13,14]$. The conventional demolition process consists of reducing the building components to smaller, easy to transport yet unusable waste. To integrate a $\mathrm{CE}$, the conventional process requires a project framework that can detect, extract, evaluate, track and receive material through the construction and demolition process [15]. Problematically, however, in the current building stock, many materials are not suitable for reuse as they were not designed for deconstruction [16]. Conversely, the selective demolition process aims to treat buildings as an ongoing source of materials-a concept known as buildings as material banks (BAMB) [17]. It is still uncertain whether designing for disassembly might lead to an increase in the uptake of deconstruction, or whether deconstruction and the availability of reusable components could encourage designers to consider including disassembly features in their designs [18].

Information that can be used to identify materials and components for reuse in advance may help to facilitate upcycling and reuse opportunities [19]. Building information modelling (BIM) is the newest generation of computer-aided design software, which acts as more than just a drafting tool. Indeed, objects designed through BIM contain smart features, for example, a window knows it belongs in a wall and the family will have attributes associated with it, which contain the size, composition and manufacturer [20]. It is this powerful processing capability that makes BIM software a logical fit for the pursuance of a $\mathrm{CE}$ in the construction industry. The comprehensive information stored within the building model can extend to contain the manufacturer's warranty, spare parts and physical load attributed to each object and to link this information to its service life. Such technology enables the first smart inventory of BAMB, a crucial step towards designing for a CE.

Similarly to BIM, one of the technological and computer-aided tools used in the construction industry is virtual reality (VR), wherein a three-dimensional computer-generated environment can be explored and within which interaction can occur [21]. Unfortunately, the development of interactive environments has been relatively expensive. A solution to this problem has been shown in research by Bille et al. [22] to import complex BIM models and visualise the data available through game engine software and VR. Despite the possibility of BIM being used to reduce waste and promote the CE of buildings, recent reviews reveal that a few examples of BIM solutions have addressed ecological efficiency during the renovation and demolition of buildings [23]. The missing link between VR, $\mathrm{CE}$ and BIM represents an unexplored research area, as BIM-based end-of-life research is the nexus of two trending topics and one established topic in the construction industry: digitalisation, CE and BIM, respectively [18].

The advantage of digital BIM models is their ability to be popularised and viewed from remote locations [19]. This study takes advantage of the broadcasting capabilities of digital BIM models. In so doing, it will help close the construction industry supply chain by linking the visual cues contained in game play demonstrating where the disassemblable features exist and linking the BIM model with future use of the disassembled components. This contribution promotes the CE while also enabling potential buyers to view the bank of materials available to them prior to the building's deconstruction. There is a clear research gap identified by Akbarieh, Jayasinghe, Waldmann and Teferle [18] (p. 22) and they state that "no BIM based EoL study has investigated the application of BIM for a building which is not only DfD based, but constructed with reusable components" (EoL refers to end of lifecycle, and DfD refers to design for disassembly). The research gap is addressed here through a case study designed with the CE framework in mind. Further, the BIM-based VR environment eliminates the precursory works required in previous BAMB, where a pre- 
redevelopment audit of the building is required, as the BoQ material mass and resilience index of building material are stated $[15,19]$.

To address the gaps in the literature, the case study methodology was adopted, implementing the CE concepts in a full-scale building (as proposed by Yin [24]). This study builds on previous work undertaken by Abdul Nabi and El-adaway [25], who conducted a review indicating that the most significant impacts of modular construction were reduced environmental impact, and material and construction waste. This review also noted that the majority of research in the field related to theoretical studies, and highlights that there is a need for these decision-making factors to be applied to actual buildings, rather than models; a sentiment which resonated in studies by Kirchherr and van Santen [26]. Researchers indicate that technology is the key aspect in creating a CE in the construction industry, combining supply and demand, as well as the handling and storage of the large amount of data that is required to give an accurate description of the material and components' origin and history [23]. In response, this study interprets the BIM model from a full-scale CE case study, named Legacy Living Lab (L3). To achieve the goal of a CE in construction, we had to answer the following research questions:

- Considering the complexity of assembling buildings, how can they be disassembled easily, thereby maintaining commercial value?

- How can the materials and components be viewed and advertised digitally, thereby implementing a digital market of used construction components?

- What design features can be implemented to guarantee that the materials and components will be safely disassembled at the end of life?

In exploring possible solutions to these questions, this study adopts a case study method to investigate the multiple disassembly methods employed in a CE case study, by linking the BIM model with game software to create a VR experience that can be used to educate designers and extend research on the CE and BAMB.

Section 2 of the paper explains the methodology adopted in this research, including details on the case study L3 and the framework of the method. Section 3 proposes the results of the integration of BIM and VR to study CE features of buildings, while Sections 4 and 5 summarise the discussion and conclusions of this research, respectively.

\section{Methodology}

\subsection{The Case Study Method}

The case study method is considered the best tool to observe and research a phenomenon in its practical context and empirical endeavour [24,27-29]. Additionally, three main reasons make the case study method an essential tool for providing insights into how to design, manufacture and document a CE prefabricated building. First, a case study method allows for the provision of a thorough explanation of how L3 (Figure 1) was designed and built to be a disassemblable CE building [30]. Second, the case study method constructs the guidelines to combine virtual platforms, such as the BIM model, to explain the barriers of manufacturing a CE building. Third, with the support of the L3 case study, we can upscale the technologies used and provide insights on further adoption of the BAMB concept, providing the material quantities and disassembly metrics. Further, practical applications have been called for in the reviewed literature to progress the construction industry towards a CE, design for disassembly and BAMB [12,18,23,25,31]. Indeed, although there are many theoretical examples of buildings and components designed for disassembly and reuse (see, for example, Akinade et al. [32] and Eberhardt et al. [33]), there is a need to integrate theory with practice [26,34]. Hence, to apply the case study method, we chose L3 as it was designed and built to prove the concept of disassembly and reuse. It follows that a thorough analysis of L3 can demonstrate the strengths and weaknesses of multiple CE strategies contained in a building designed for disassembly. In conjunction with the VR environment and the features of BIM technologies, the case study method guided us to address our research questions. This method unfolds in four main steps, adapted from Tellis [35] (Figure 2). 


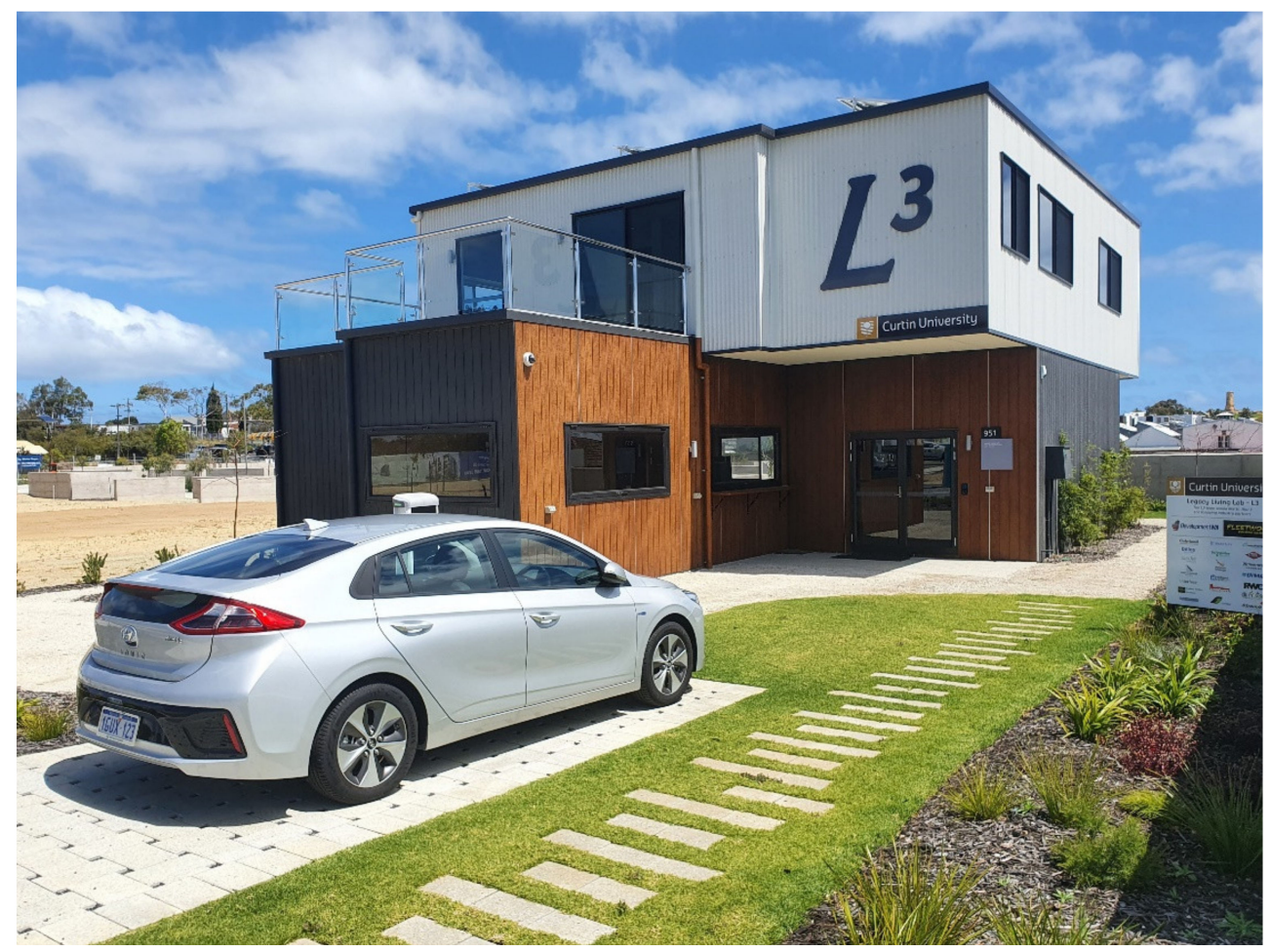

Figure 1. The case study selected for this research: the Legacy Living Lab (L3).

\begin{tabular}{|c|c|c|c|}
\hline $\begin{array}{c}\text { 1. Case study design and } \\
\text { construction }\end{array}$ & 2. Detail design & 3. Sample analysis & 4. Reporting \\
$\begin{array}{c}\text { Design of the L3 case } \\
\text { study and application of } \\
\text { the design strategies. }\end{array}$ & $\begin{array}{c}\text { Modelling on BIM and } \\
\text { hierarchy based on } \\
\text { material parameters and } \\
\text { functions }\end{array}$ & $\begin{array}{c}\text { Integration of the BIM } \\
\text { model into a VR game } \\
\text { engine }\end{array}$ & $\begin{array}{c}\text { Actions within the VR } \\
\text { environment reported. The } \\
\text { CE initiatives described in } \\
\text { parallel to the model. }\end{array}$ \\
\hline
\end{tabular}

Figure 2. Methodological framework adopted in this study.

Case study design and construction (1). In this step, we designed and documented each step of the construction of the L3 case study building. In opposition to the traditional linear economy construction methods, L3 is a case of a CE in construction (i.e., not the typical modus operandi). Throughout the year of design, we used the knowledge one of the authors of prefabricated buildings to select the most problematic barriers to achieving a CE in construction and began to explore the ways these barriers could be removed with identified CE strategies implemented. The strategies have been defined in Minunno et al. [36] and are presented in Table 1.

Table 1. Seven strategies found by Minunno et al. [36] that were implemented in the L3 case study.

\begin{tabular}{cr}
\hline & Strategy \\
\hline 1. & Reduction of construction waste and the lean production chain \\
2. & Integration of scrap material, waste and by-products into new components \\
3. & Reuse of replacement parts of entire components \\
4. & Design towards adaptability (reduction through life extension) during operational stages \\
5. & Design towards disassembly of goods into components to be reused \\
\hline 6. & Design for recycling of construction materials \\
7. & Systems to track material and components within their supply chain \\
\hline
\end{tabular}

Detail design (2). The selected design details were collected and the assembly process was reported within the BIM model. Once design details were collated, we categorised 
them according to the seven CE strategies identified in Table 1. We also associated a hierarchy based on the material parameters and functions (e.g., reduce, reuse or recycle), the material connections and the details of what was behind the visible finishes in the building (e.g., non-visible service ducts designed towards adaptability). It should be noted that BIM is the practice of creating and maintaining the BIM model; therefore, the term BIM model will be used throughout the remainder of the paper.

Sample analysis (3). Once the building was completed, we analysed the CE features of the building and merged the BIM model into the VR game engine to ensure the technical and physical characteristics were correct. A selected number of the hidden features were added to the VR model to ensure that a visual cue would prompt users to navigate the VR environment and learn the importance of details hidden or inaccessible to them. A green icon of a recycling symbol was selected as the visual cue and select panels would raise, drop or lower to provide a visual experience behind walls and ceilings, as a voice over described the reasoning behind the design details and the benefits to the environmental sustainability of the building project.

Reporting (4). In this step, we reported the actions within the VR environment and described in detail the CE initiatives in parallel to the model. This step was crucial as it distilled best practice alternatives when designing and assembling a disassemblable building, based on a successful case study example.

\subsection{Case Study Description and Study Boundaries}

In this study, we analysed the VR environment of the L3 prototype's digital twin (Figure 1). L3 is an eight-module prefabricated building that we designed and built to demonstrate the CE applicability through the disassembly and reuse of building components. L3 was built at a dedicated prefabricated manufacturing facility in Perth, Western Australia. L3 has a floor area of $251 \mathrm{~m}^{2}$ divided into two floors and includes a commercial area and café space on the ground floor and an open office area with a shared kitchenette on the first floor. The ceiling and internal cladding were designed to be fully disassemblable, granting access to the insulation and mechanical and electrical plant services without creating any waste (Figure 3). The ground floor and first floor of the prototype L3 are designed explicitly for adaptability. The design has large open spaces that can be closed for future use and redundant features, such as service ducts and elevator reveals, for future adaptability. The structure is built using heavy-gauge steel chassis and columns, light-gauge steel wall frames and particle-board floors; the external cladding is pressed timber on the ground floor and corrugated steel sheets on the first floor and roof. Internal cladding is composed of plywood sheets, plasterboard and acoustic ceiling panels (as shown in Figure 3). In this study, we limit our study boundaries to the CE initiatives embedded in the L3 project to promote the learnings and facilitate a rapid development of a CE in the construction industry, which, in turn, can be facilitated by the sharable VR environment.

\subsection{Virtual Reality Methodology and Workflow}

The workflow used in this study is similar to that explored by other researchers [22,37]. This research positions itself in the same VR environment with the hope of better education of building practitioners by visualising how a CE can be practically implemented in buildings (Figure 4).

\subsubsection{Preparing the Revit Model}

BIM is a better way to visualise, communicate and share knowledge among disparate actors in the construction industry because 3D models are much closer to everyday reality than their 2D paper predecessors [38]. The preparation of the BIM model in Autodesk Revit 2019 (San Rafael, CA, USA) was crucial as once the model is exported to Unity, there are minimal modelling capabilities once the change in software is made. Unity is, however, a powerful tool for developing real-time interactions with the 3D geometry. Initially, the BIM model was difficult to work with as the industry partner contracted to build the L3 
case study did not achieve the correct level of design when drafting the BIM model. The BIM model was created as if the building was to be constructed as a monolithic structure, built in a traditional method, and, therefore, did not replicate the modular prefabricated aspect of the case study. The result of this drafting technique was that each of the ground floor and first floor modules needed to be separated and exploded prior to their export to Unity to reflect the building's modular characteristics.

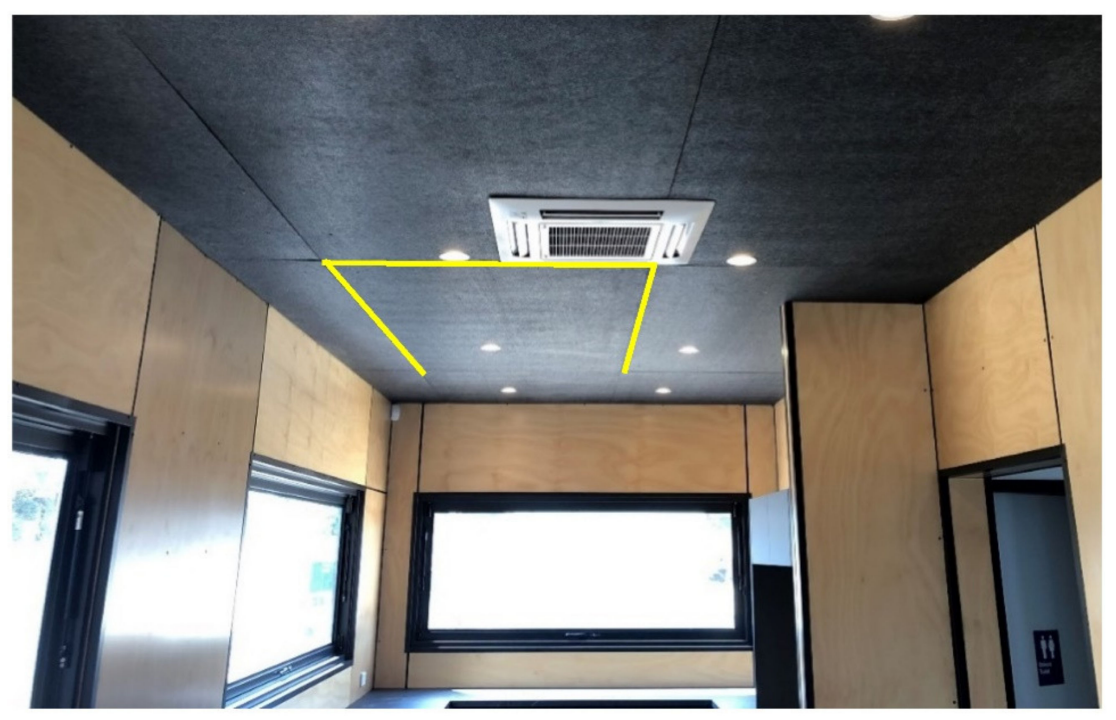

Figure 3. Disassemblable and resilient ceiling and cladding.

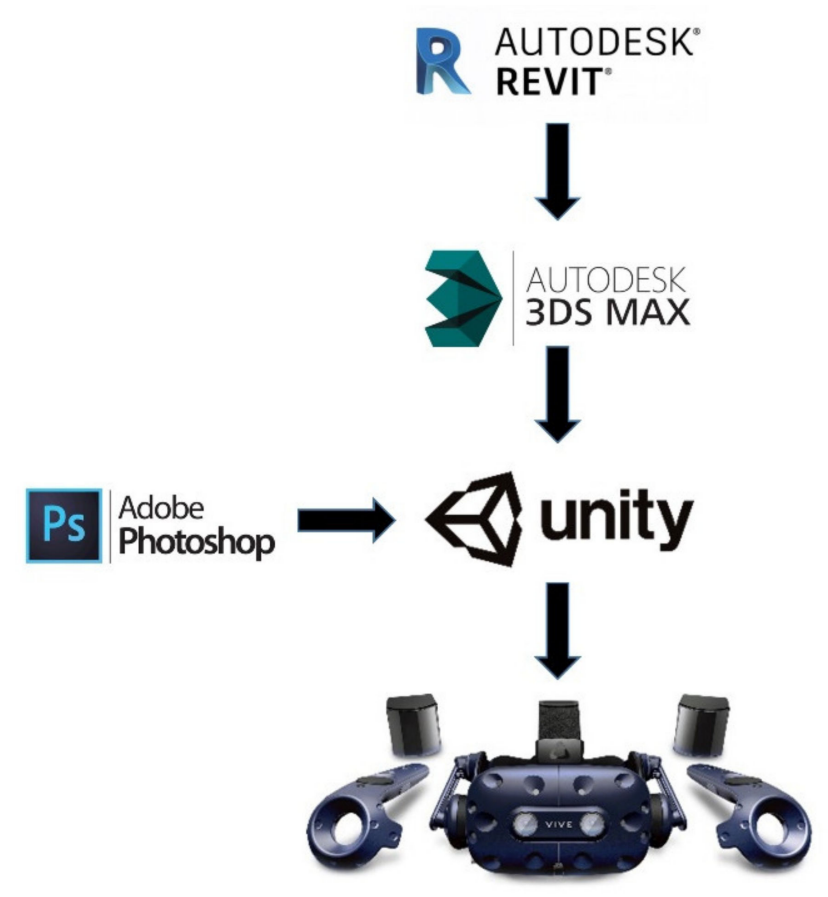

Figure 4. Programs used to create the virtual reality (VR) experience and workflow sequence.

\subsubsection{Exporting from Revit}

Once the BIM model had been prepared in Revit, each module was assigned its own viewport and view name in the software for convenience. The film box (FBX) file format was used to export from Revit; however, lighting and materiality links are not optimised when making the shift directly from Revit to Unity 2019 (San Francisco, CA, 
USA). Therefore, 3Ds Max was used as a stepping stone to avoid having to manually fix the lighting and material finishes between Revit and Unity.

\subsubsection{DS Max}

Autodesk 3ds Max 2019 (San Rafael, CA, USA) is a professional 3D computer-generated graphics program for creating assets and animations and was ideal for correcting lighting and material finishes available in Revit. Within 3ds Max, actions were taken to enhance how the 3D BIM geometry would perform in the game engine, Unity. In 3ds Max, the 3D model geometry map settings were changed to box mapping. This change enabled the texture of elements within the model to be tiled, as opposed to the 3D (UVW) mapping, which stretches texture across the surface. The result of this change was a superior rendering and surface detail within the BIM model. Once the corrections to each module had been made, the Revit FBX exports were replaced with a new 3ds Max FBX export file ready to be imported to Unity. Unlike the FBX format exported from Revit, Unity recognised the lighting information from the FBX files exported from 3ds Max.

\subsubsection{Importing to Unity}

The Unity project browser can quickly become filled up and unorganised if not properly managed; thus, folder and file name management is key to managing complex projects in Unity. To combat this issue, import data were managed by creating individual folders for each of the eight modules. Once imported to Unity, the FBX files were organised into a project hierarchy, then into a scene, in which the VR development begins.

\subsubsection{Materials and Lighting}

To create the best visual representation within the VR environment, material textures were captured using a Canon EOS 200D digital single lens reflex (DSLR) camera (sourced in Perth, Australia). The pictures taken from the built example of L3 were then processed in Photoshop, with the images uniformly cropped to enable them to be tiled as a texture in Unity. Imported custom textures were located in corresponding module folders to maintain organisation within Unity. Once textures had been finalised, the materials were covered by selecting the surface and assigning the correct material finish. A feature of Unity is that surfaces throughout the model that share a material will all update when one change is made. This was particularly applicable for components such as furniture or electrical power outlets which were largely numbered throughout the model, meaning changing them one by one would not have been feasible.

\section{Results}

A total mass of 36.3 tonnes was used in L3, including steel (61\%) and timber (26\%). Of the materials used, $58 \%$ were disassemblable and reusable multiple times. The results section is organised according to the seven strategies defined in Table 1.

\subsection{Reduction of Waste and Lean Supply Chain}

The introduction to the VR environment begins with the hero image (Figure 5a). Once the participant selects the play button by grabbing the icon, the voiceover starts and explains the benefit of building with modular prefabrication. The eight individual modules fall into position in the sequence in which they were erected on site (Figure $5 b$ ). Modular prefabrication lends itself to a CE in its early stages as buildings are designed to be easily transported to site. Buildings that are designed to be lifted into a position and transported also have the ability to be relocated in the future [39]. Prefabrication has the added advantage of lean supply chain management and the ability to appropriately store and manage waste products in the manufacturing facility, reducing the amount of mixed waste going to landfill [40]. 


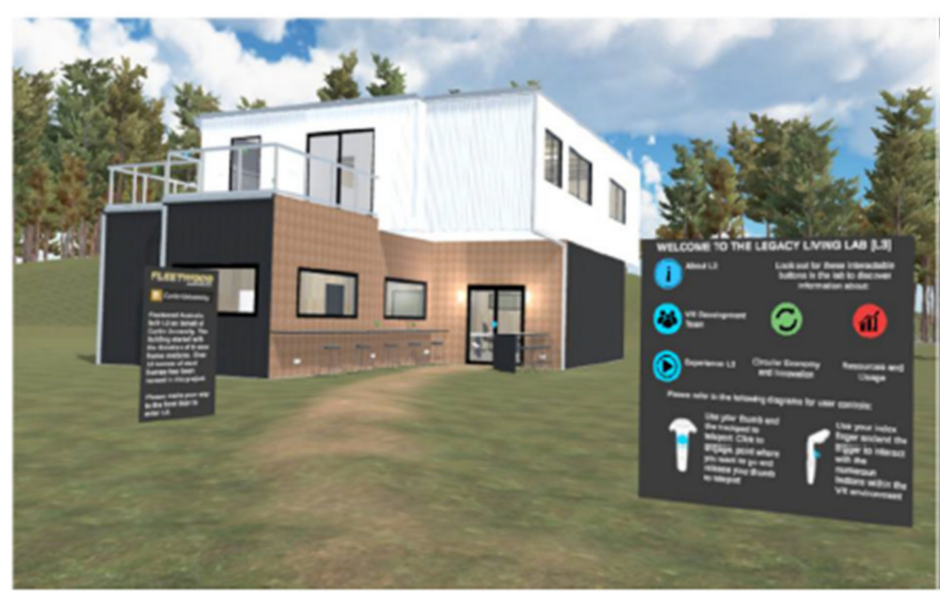

(a)

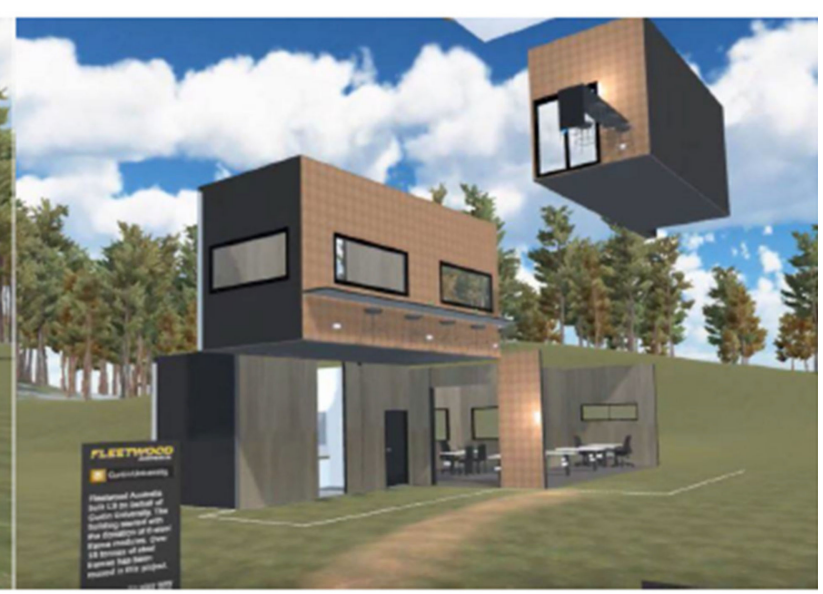

(b)

Figure 5. (a) Hero image is the starting sequence for the VR environment. (b) Modules falling into position show how the building was installed on site in the construction sequence.

\subsection{Integration of Scrap Material, Waste and by-Products into New Components}

The total weight of reused material in the L3 prototype is just under 17 tonnes (Figure $6 a, b)$. This is limited to materials that were $100 \%$ reused and does not consider partial integration of recycled feed stock into new materials (Table 2). Further to the materials used in the structure of the building, all furniture used in L3 is in its second lifecycle.

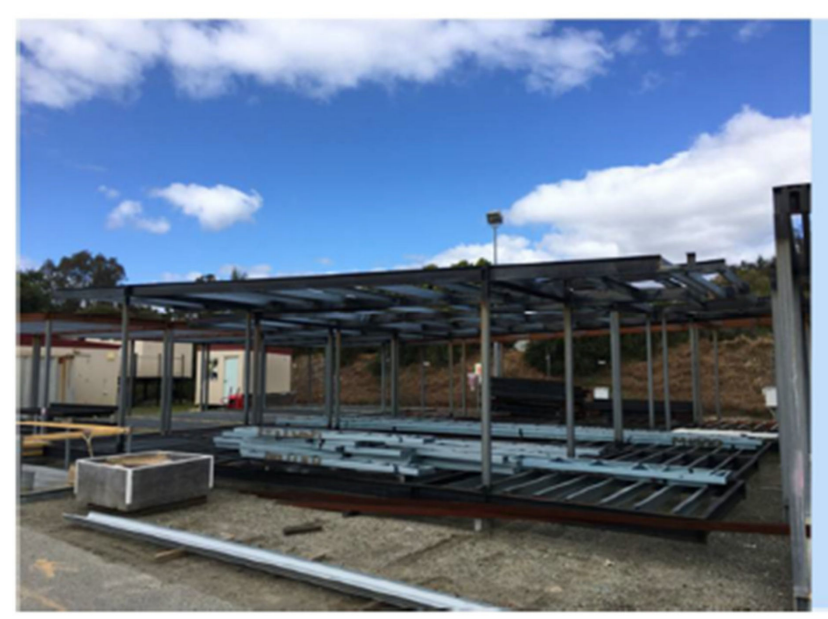

(a)

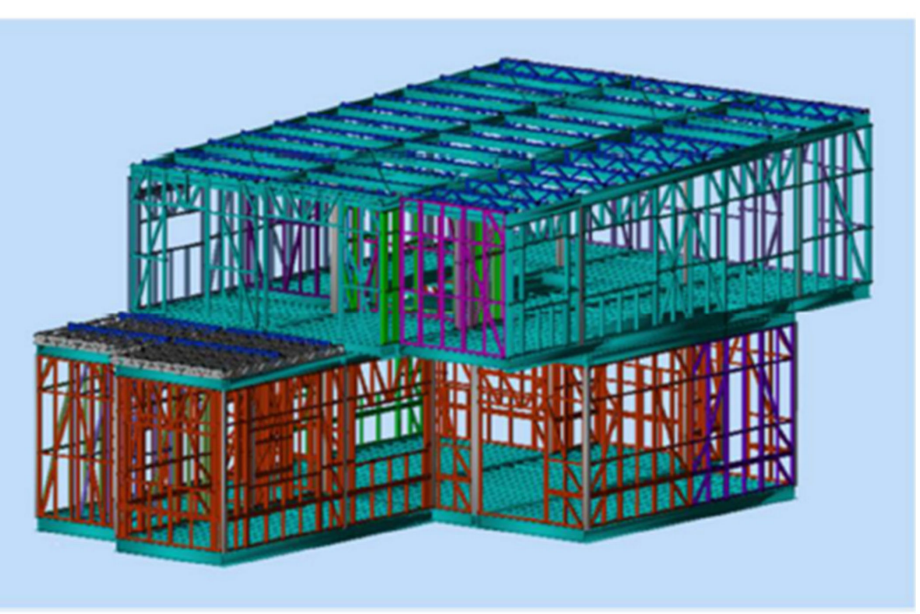

(b)

Figure 6. (a) The starting point for the project was the reused structural steel frames. (b) The steel frames reimagined in Framecad software.

Table 2. Weight of materials that were reintroduced into the L3 prototype.

\begin{tabular}{ccc}
\hline Component Description & Material Resilience & Mass (kg) \\
\hline Steel chassis and load-bearing structure & $(\mathrm{In})$ & $16,138.9$ \\
Reused timber stair treads & $(3 \mathrm{t})$ & 164.0 \\
Carpet covering $193 \mathrm{~m}^{2}$ of internal floors & $(3 \mathrm{t})$ & 183.4 \\
Stairway steel structure & $(\mathrm{Rc})$ & 422.8 \\
Total weight & & $16,909.1$ \\
\hline
\end{tabular}


This was possible through the relocation of furniture from Curtin University to the first life of the building in its first location, the nearby city of Fremantle (Western Australia). The carpet tiles used in L3 were completely salvaged from a retrofit project, wherein the tiles were dated after three years and the new tenant of the building wanted them to be replaced. Due to our industry partner having a strong business model for the CE, the tiles were removed from the site and stored in the factory for second-hand stock to be sent back to the east coast for recycling. Fortunately, the recycling and transportation process was circumvented by using the tiles in the L3 project. Despite this, the example of the tiles further demonstrates that closed-loop supply chains of building components are missing, and it also shows that there is demand for such reuse; a VR model integrated with BIM would foster this vision of a commerce of reused materials.

\subsection{Integration of by-Products}

Where reused materials were not readily available, new materials with high recycled content were selected. The kitchens, both upstairs and downstairs, contain recycled material in their production. Approximately $25 \%$ of the chipboard in the cabinets is made from end-of-life timber, such as pallets. Similarly, the acoustic ceiling panels are made from a mix of new and recycled PET plastic with a recycled content of $70 \%$. The balcony tiles are made from recycled rubber and plastic waste (Figure 7). The blending of these two materials produced a resilient, modular paving solution for the building, which is also permeable, making it a perfect fit for the design of the balcony. The modular, interlocking design means that the tiles can be lifted and reused in future scenarios.
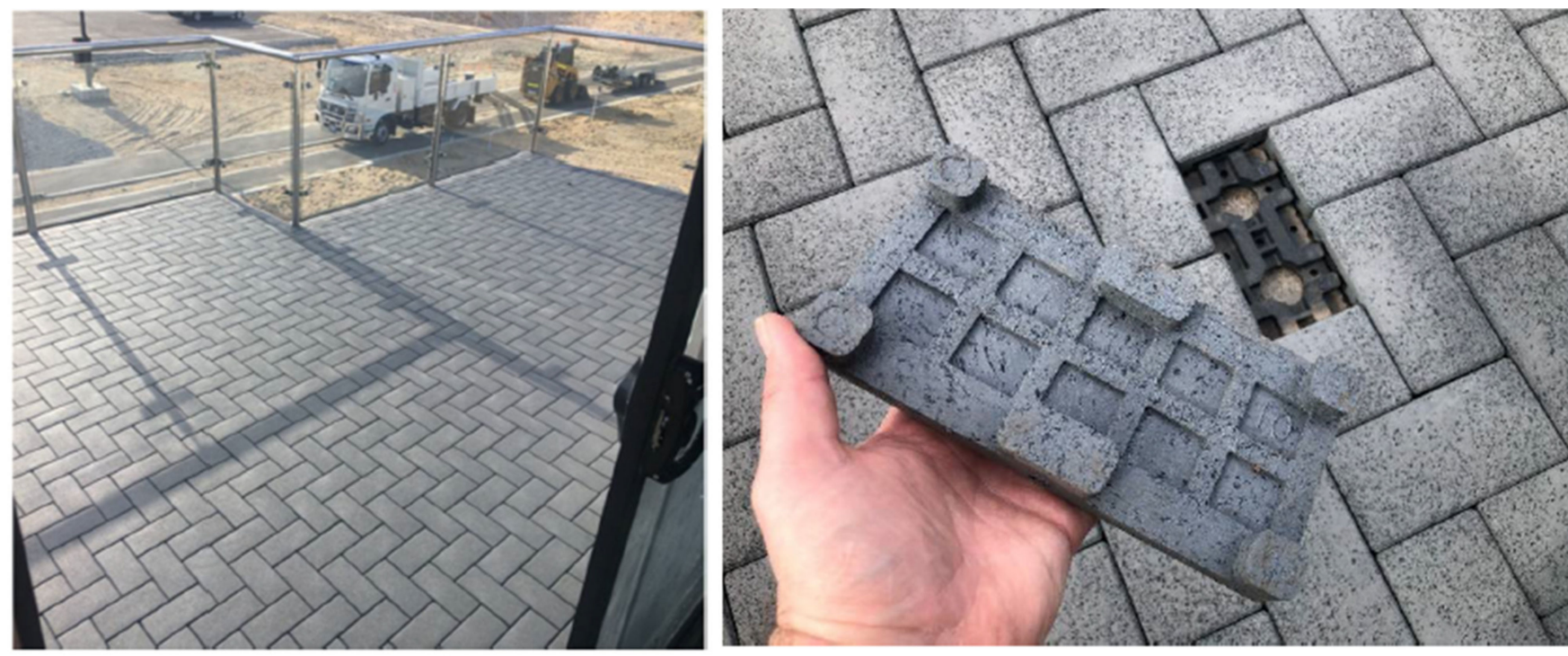

Figure 7. Balcony tiles made from recycled rubber and plastic waste.

\subsection{Reuse of Replacement Parts or Entire Components}

The kitchen is an example for which we can often find replacement parts and components that can be reused in the construction industry. A prime example is the water chiller and filtration units, which were salvaged from a demolition site. The lines and filter were replaced and the components were introduced to their second life (Figure 8a,b). Components such as the water chiller and filtration unit embed substantial amounts of energy and carbon, yet when the buildings in which they are located are demolished, these components are often lost within [41]. Replacement of building parts, components or fittings will substantially reduce buildings' embodied energy and carbon and VR models may help interested buyers to obtain these parts for a fraction of their price when a proprietary building is demolished. 


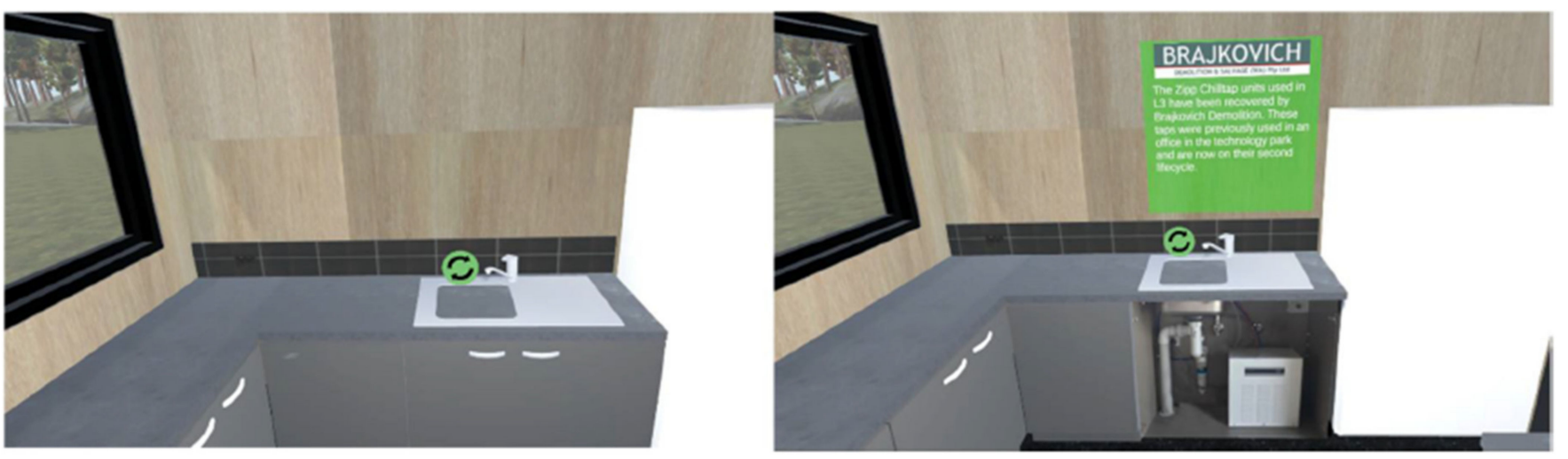

(a)

(b)

Figure 8. (a) The recycling logo prompts participants to learn about the provenance of the water chiller and filtration used within L3. (b) On the right, the figure shows the salvaged component within the VR model.

\subsection{Design towards Adaptability (Reduction through Life Extension) during Operational Stages}

Although gypsum is a recyclable material, in most refurbishment practices, walls are stripped bare of plaster and insulation, resulting in an extreme amount of waste in the renovation process [42]. To overcome this, a wall covering system that replaced plaster and resulted in more resilient properties was implemented through removal of a wet fixed joint system. The wall design consists of a negative detail plywood wall lining system, comprising aluminium negative detail strips and marine-grade plywood. The wall lining enables all wall panels to act as access panels, providing access to $82 \%$ of the building's internal walls.

The service duct is hidden behind two large access panels and supplies a service corridor from the roof space of the building to the ground floor (Figure 9a,b). This feature is crucial for potential future fit-outs in the building, in which new technology will be prototyped. Having redundant features designed into the building creates a reduction in waste through the life extension of a product (Strategy 2). However, because such redundant features are typically hidden, they risk oversight in future uses of the building and may not be employed at the right time. To avoid this issue, a VR model of the building empowers the designers and users, who will then be able to make the existing building adaptable to further uses before working on the envelope itself.

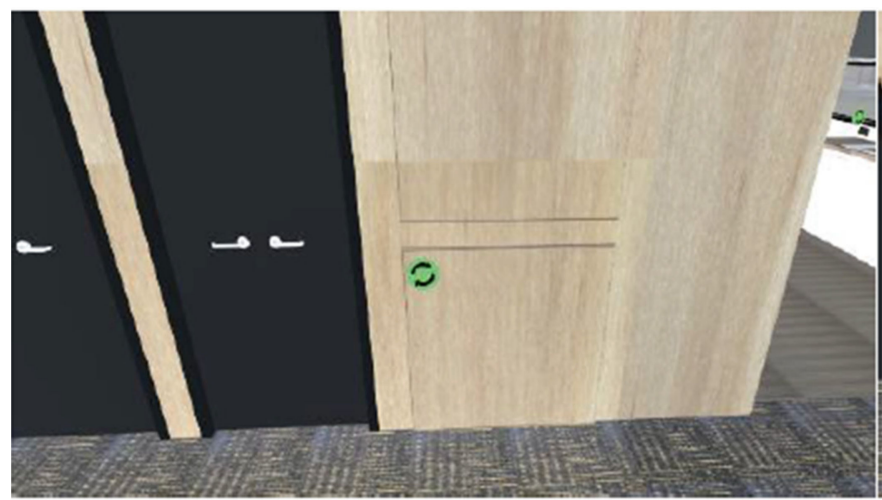

(a)

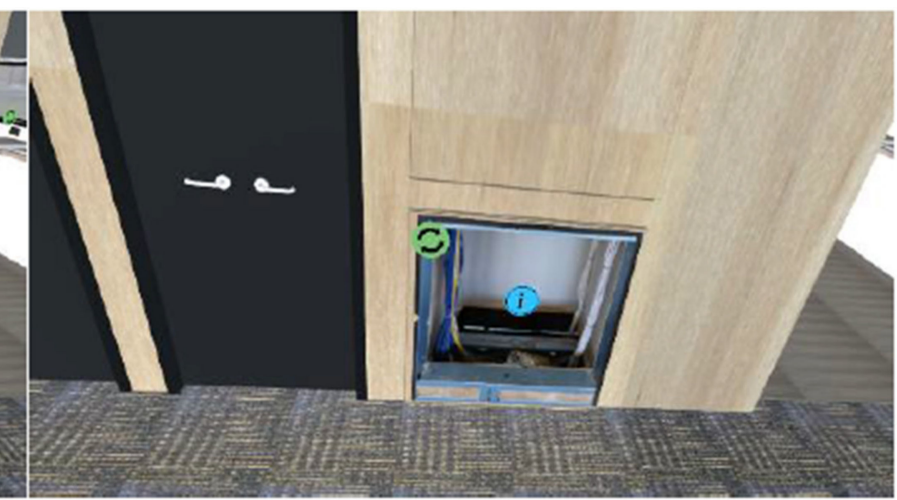

(b)

Figure 9. (a) Wall panelling hides the service duct connecting the roof space to the first floor and ground floor ceiling. (b) VR model exposes the lower access panel, revealing the service duct.

Disassemblable wall panels achieve Strategy 4. Plywood wall panels are resilient and have an external fixing method by means of a screw fixing, which enables easy access to 
internal and external wall services, such as electrical cables and insulation. Again, the panelised design has been achieved by implementing the use of industry standard sizes or multiples thereof.

\subsection{Design towards Disassembly of Goods into Components to Be Reused}

To ensure that the carpet tiles have a possible third life, no wet-setting contact adhesive was used to fix the tiles to the substrate. The tiles are held in position using a double-sided tactile pad, which helps aid the removal and replacement of damaged tiles and facilitates a better recycling process at the end of life.

The ceiling panels used in the L3 are an acoustic felt product (Figure 10). These acoustic panels are also disassemblable and magnetically fixed into position. This enables Strategies 2, 4 and 5 to be achieved. Specifically, Strategies 4 and 5 were achieved by designing the panels to be accessible. With the magnets attached to the building structure and a steel frame backing on the panels, the panels can be easily removed to facilitate a re-fit of technology. Designing the panels to use standard industry sizing as much as possible means that at the end of life, the majority of the panels can be removed and reintroduced to the next building project.

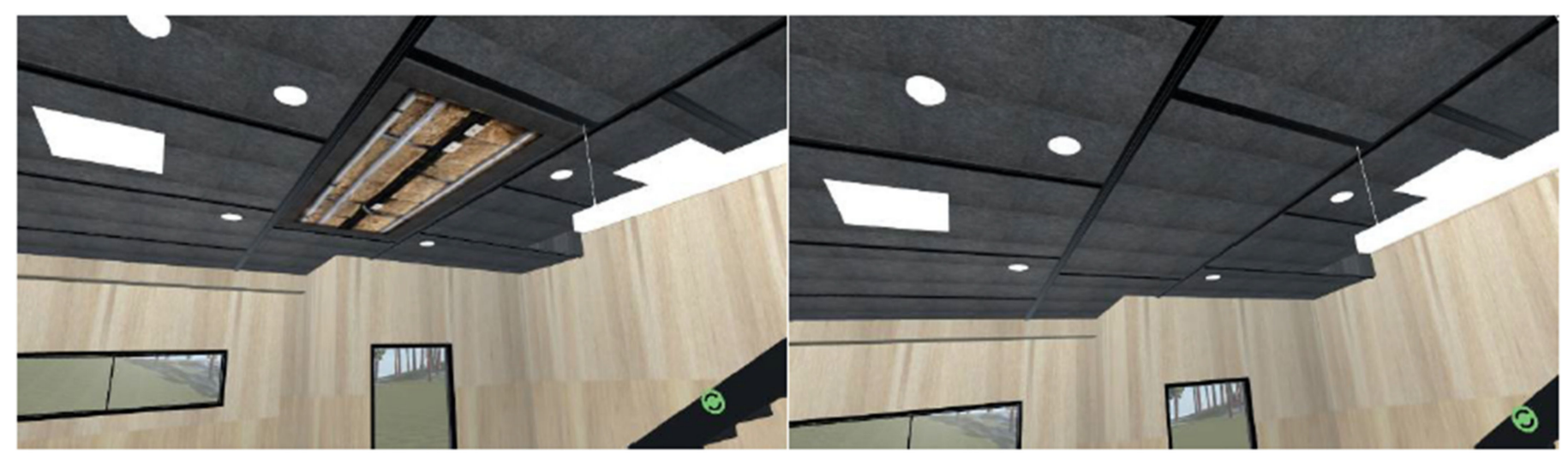

Figure 10. Acoustic felt ceiling panels reveal insulation and allow access to mechanical and electrical plant services throughout the multiple lifecycles of the building.

\subsection{Design for Recycling of Construction Materials}

The staircase image in the VR model shows the external wall behind the stairs to demonstrate the modularity of the wall structure (Figure 11). The walls have been split into $1200 \mathrm{~mm}$ sections, which can be individually removed in case of expansion or modification of the project. Having discontinuous wall frames achieves a higher chance of disassembly over demolition as the weight from the wall section is reduced. Reducing the weight of the building elements increases the chance of removal as weight can be directly translated to cost of disassembly. If the product is heavy or cumbersome, there will need to be mechanical controls, such as a crane, forklift or even scaffold or bracing, to remove it or relocate the material. If the object does not require as much mechanical assistance but still necessitates a two-man lift, the labour rate of the removal will be instantly doubled. These factors all play a part in the adoption of a CE in the building industry.

\subsection{Systems to Track Material and Components within Their Supply Chain}

The power board in the model does not show the CE strategies used within the building, as it was designed to lead into the future stages of the VR to investigate the operational energy required by the building. The building has 19 tracked power circuits and the information can be visualised on the screens within the building and within the game model on the monitors. This links with Strategy 7, as it highlights the importance of tracking consumables, as well as the material flow within the building, and helps towards reducing buildings' energy consumption [43]. 

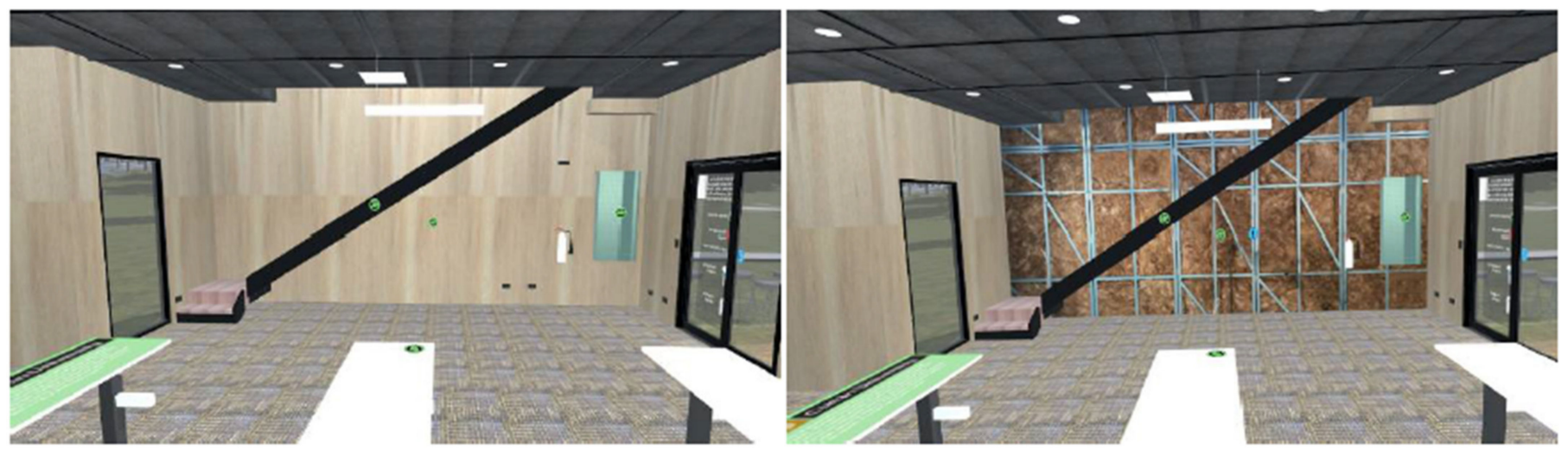

Figure 11. The VR model allows visualisation of the modular construction elements.

\section{Discussion}

This research has successfully demonstrated the implementation of seven identified CE design initiatives applicable to the built environment, and their integration with VR environments, thus filling a noticeable gap in the literature [44]. The BIM model, which accurately represented the L3 case study, was transformed into a VR experience through 3ds Max with the aid of Photoshop processing tools and into the final experience in Unity. Overall, six game play triggers revealed hidden elements of the building as voiceovers educated the viewer how to design for a CE. The BIM model also holds within itself the BoQ for the projects, enabling the second benefit to research, as it visualises the current material stock available to purchase at end of life, and shows the assembly sequence of the building to assist with end-of-life disassembly, bridging significant literature gaps discussed by Akbarieh et al. [18]. This research limits the need for potential buyers to visit the site to understand the space, as the model can be shared online, enabling it to be experienced globally. Therefore, prior to deconstruction, the material available and the visual aesthetics of the material are viewed and, thus, can be procured for second life. The popularisation of materials has the potential to divert large amounts of waste from landfill. In so doing, the proposed research proves that the integration of digital twins in VR environments, facilitated by the adoption of BIM, extensively enhances the applicability of CE strategies. In short, CE strategies can successfully be applied to modular buildings, and digital technologies are powerful tools for practitioners and designers. For example, being able to visualise construction details such as cavities hidden by cladding panels without the need for disassembly of the walls is a capability that might enhance integrated design towards waste minimisation.

\section{Conclusions}

\subsection{Main Implications}

This study proposed the application of CE principles to the building context and integrated these principles with BIM and VR tools. In so doing, this study makes three main implications that extend the research in the field of VR, CE and BIM towards BAMB. These implications can be adopted by scholars and practitioners in the field of VR and sustainability of buildings. First, the interactive nature of the experience will give building designers the foundations to design for a CE (a concept similarly explored by Jamei et al. [45]). Indeed, although design concepts and strategies might have been applied thoroughly to buildings, they risk being overseen once the buildings are cladded and finished. Therefore, through the application of VR tools, these efforts can be further visualised and studied. Second, VR models act as a visualisable BoQ for parts that can be safely dismantled, forming an induction for future renovation, disassembly, deconstruction or demolition work (a concept similarly studied by Matipa et al. [46]). Third, it enables the building to be viewed and interacted with globally, without the need to travel to the site, which is particularly important 
for education, especially considering the current circumstances surrounding the COVID-19 pandemic as well as future learning settings [47,48].

Finally, this building is an early example of visualising BAMB strategies, as it shows the parts available for reuse. L3 was designed for disassembly and deconstruction; therefore, its components can be removed and recirculated within the material supply chain without the creation of waste. This was achieved through a series of design advances that see the building being bolted into position with little chemical connection (i.e., concrete or glues). A unique flashing method was implemented to solve the issue of having a waterproofed balcony that could still be disassembled. The balcony makes use of a traditional silo flashing design, which enables it to be watertight and concealed under the external balcony paving. Due to these considerations at the end of life, this project can be disassembled and relocated while only producing $1 \%$ of its mass as waste. The disassembly at the ultimate end of life enables $64 \%$ of the building to be reused or recycled. This research has revealed the measures that make these figures achievable, demonstrating how the industry can learn through this virtual model.

Material selection was crucial in the design process and followed the hierarchy of the three Rs (reduce, reuse, recycle). With material reduction being achieved by applying the modular prefabricated building typology, the top rung on the hierarchy was to reuse as many building materials as we could access. This was achieved by using eight steel-framed structures that were salvaged from a failed building project to create the structure of the building. The staircase was also reused material, with the stair treads being salvaged from a local factory, and the stringers fabricated from another existing structural steel frame. Other components that were reused include carpet tiles and all furniture throughout the building, which was relocated from departments in which it was no longer required at the university. Where complete reuse was not an option, materials with recycled content were favoured over those constructed entirely of virgin materials. All cabinets contain $25 \%$ recycled end-of-life timber and the acoustic ceiling panels contain 70\% recycled PET bottles to form the feedstock for their production line.

\subsection{Limitations and Future Research}

Due to limited research on a number of the building products that we have used in L3, future research will be required on their recyclability. For example, the balcony tiles contain a significant amount of recycled material; however, the quantities and design life are relatively unknown as a result of the new release of the product. The end-of-life pathway and potential off-gassing of volatile organic compound emissions need to be investigated. The current location of the balcony tiles is exposed to direct sunlight from sunrise to 12:00 p.m., so a longitudinal study of their performance in this application could prove advantageous. Further, there has not been a study on the $\mathrm{R}$ value of the tiles (at the time of this publication). The transmissibility of heat through the tiles will help designers assess their use in second floor balcony systems and eliminate the need to over-insulate in the service of caution, as was required in the case study.

There is a need for the development of material banks and sales platforms for the construction industry. Currently, in Australia, there is limited access to good-quality second-hand construction material for industry. Each country should have a commitment to advertising the materials available to reduce the likelihood of materials being discarded as a consequence of difficulty finding a buyer. The identified research aims to bridge the gap in advertising the materials available before the deconstruction of the building to reduce the hold time and laydown space required in performing the transaction between building material removal and building material collection and purchase. Digitisation can be increased, as this sole example gives prospective buyers the opportunity to physically interact with and see the objects in the VR model; hence, there is no difficulty in judging their size or appearance.

The level of design could be significantly improved in future projects. The original model drafted by the industry partner reflected a traditional model of the building designed 
to be built in situ. Once the design was past the architect's revision process, the model was locked, and future iterations of design were not added. For this reason, connection details, drawn by the steel design teams, were not retrospectively added to the original model. Internal elements were drawn as flat lines to save time, which meant that we had to rely on adding the materials ordered by delivery dockets and purchase orders, rather than executable files contained within the BIM model.

These are the very early stages of the BIM-VR models and the integration between BIM and higher quality VR software, such as Matterport, needs to be researched and their potential to link together must be resolved. Such integration will enable real-life imagery and remove the need to use generic families to represent soft furnishings, such as desks or custom furniture, for which the BIM family may not yet be available, or negate the need to design them into the software.

Future works will study ways to link live energy data, taken from buildings' energy management systems, and display this energy data in the model so that appliances of high consumption can be highlighted to bring them to the forefront as targeted reduction schemes. The live energy data will be displayed in the PORTAL next to the embodied energy of the products from the games list, so that there can be a comprehensive understanding of materials and their carbon footprint. This will give future designers the ability to design solutions for improved results and, thus, to contribute to a better built environment.

This paper captures the work necessary to create a VR from Revit; however, there needs to be a greater connection to Matterport and point cloud technologies to enmesh the different softwares to create a simplified process.

Author Contributions: Conceptualization, T.M.O. and N.B.; methodology, T.M.O. and R.M.; software, N.B.; formal analysis, T.M.O. and N.B.; writing—original draft preparation, T.M.O.; writingreview and editing, T.M.O., R.M., H.-Y.C. and G.M.M.; visualization, N.B. and T.M.O.; supervision, T.M.O.; funding acquisition, G.M.M. All authors have read and agreed to the published version of the manuscript.

Funding: This research was funded by Australian Research Council's Centre for Advanced Manufacturing of Prefabricated Housing (CAMPH), grant number IC150100023 and the Western Australian Government Jobs, Tourism, Science and Innovation PhD Fellowship program, grant number J0546/201801. The APC was funded by Curtin University.

Institutional Review Board Statement: Not applicable.

Informed Consent Statement: Not applicable.

Data Availability Statement: The data presented in this study are available on request from the corresponding author. The data are not publicly available due to technical constraints.

Acknowledgments: The authors wish to acknowledge funding from the Australian Research Council's Centre for Advanced Manufacturing of Prefabricated Housing (CAMPH; grant number IC150100023) and the Western Australian Government Jobs, Tourism, Science and Innovation PhD Fellowship program (grant number J0546/201801). This project was conducted as part of the Curtin HIVE Summer Internship Scheme and supported by the Curtin HIVE visualisation facility and the following industry partners and businesses were involved in the creation of the Legacy Living Lab: Acoufelt, Armstrong Flooring, BlueScope, Brajkovich Demolition and Salvage, Clipsal by Schneider Electric, Delos, Development WA, Enware Australia, Fleetwood Australia, Gunnersen Timber, Infinite Energy, Intelligent Home, Interface Flooring, Innovative Timber Ideas, Jason Windows, Ludlow Timber Products, Metforce Ballustrades, Met-tech Imaging, Proform, Reliance Worldwide Corporation, Stramit, Weathertex and Zimi. This work was supported by the ReNEW Nexus project and CAMPH; however, neither were involved in the study design, the collection and analysis of data, the report writing or the decision to submit the article for publication.

Conflicts of Interest: The authors declare no conflict of interest. 


\section{References}

1. Solís-Guzmán, J.; Marrero, M.; Montes-Delgado, M.V.; Ramírez-de-Arellano, A. A Spanish model for quantification and management of construction waste. Waste Manag. 2009, 29, 2542-2548. [CrossRef]

2. Ajayi, S.O.; Oyedele, L.O.; Bilal, M.; Akinade, O.O.; Alaka, H.A.; Owolabi, H.A.; Kadiri, K.O. Waste effectiveness of the construction industry: Understanding the impediments and requisites for improvements. Resour. Conserv. Recycl. 2015, 102, 101-112. [CrossRef]

3. Kayvani, K. Tall buildings-Past and present trends. Civ. Eng. Mag. South Afr. Inst. Civ. Eng. 2015, $23,42-44$.

4. Vefago, L.H.M.; Avellaneda, J. Recycling concepts and the index of recyclability for building materials. Resour. Conserv. Recycl. 2013, 72, 127-135. [CrossRef]

5. Oikonomou, N.D. Recycled concrete aggregates. Cem. Concr. Compos. 2005, 27, 315-318. [CrossRef]

6. Tam, V.W.Y.; Tam, C.M. A review on the viable technology for construction waste recycling. Resour. Conserv. Recycl. 2006, 47, 209-221. [CrossRef]

7. Minunno, R.; O'Grady, T.; Morrison, G.M.; Gruner, R.L. Investigating the embodied energy and carbon of buildings: A systematic literature review and meta-analysis of life cycle assessments. Renew. Sustain. Energy Rev. 2021, 143, 110935. [CrossRef]

8. Lawson, N.; Douglas, I.; Garvin, S.; McGrath, C.; Manning, D.; Vetterlein, J. Recycling construction and demolition wastes-A UK perspective. Environ. Manag. Health 2001, 12, 146-157. [CrossRef]

9. Minunno, R.; O'Grady, T.; Morrison, G.M.; Gruner, R.L. Exploring environmental benefits of reuse and recycle practices: A circular economy case study of a modular building. Resour. Conserv. Recycl. 2020, 160, 104855. [CrossRef]

10. Kirchherr, J.; Reike, D.; Hekkert, M. Conceptualizing the circular economy: An analysis of 114 definitions. Resour. Conserv. Recycl. 2017, 127, 221-232. [CrossRef]

11. Stahel, W.R. The circular economy. Nat. News 2016, 531, 435. [CrossRef]

12. Adams, K.T.; Osmani, M.; Thorpe, T.; Thornback, J. Circular economy in construction: Current awareness, challenges and enablers. Waste Resour. Manag. 2017, 170, 15-24. [CrossRef]

13. Coelho, A.; de Brito, J. Economic analysis of conventional versus selective demolition-A case study. Resour. Conserv. Recycl. 2011, 55, 382-392. [CrossRef]

14. Ghisellini, P.; Ripa, M.; Ulgiati, S. Exploring environmental and economic costs and benefits of a circular economy approach to the construction and demolition sector. A literature review. J. Clean. Prod. 2018, 178, 618-643. [CrossRef]

15. Copeland, S.; Bilec, M. Buildings as material banks using RFID and building information modeling in a circular economy. Procedia CIRP 2020, 90, 143-147. [CrossRef]

16. Densley Tingley, D.; Cooper, S.; Cullen, J. Understanding and overcoming the barriers to structural steel reuse, a UK perspective. J. Clean. Prod. 2017, 148, 642-652. [CrossRef]

17. Gepts, B.; Meex, E.; Nuyts, E.; Knapen, E.; Verbeeck, G. Existing databases as means to explore the potential of the building stock as material bank. In Proceedings of the IOP Conference Series: Earth and Environmental Science, Brussels, Belgium, 5-7 February 2019; IOP Publishing: Bristol, UK, 2019.

18. Akbarieh, A.; Jayasinghe, L.B.; Waldmann, D.; Teferle, F.N. BIM-based end-of-lifecycle decision making and digital deconstruction: Literature review. Sustainability 2020, 12, 2670. [CrossRef]

19. De Tudela, A.R.P.; Rose, C.M.; Stegemann, J.A. Quantification of material stocks in existing buildings using secondary data-A case study for timber in a London Borough. Resour. Conserv. Recycl. X 2020, 5, 100027.

20. Anderson, A. Visualization, Communication, and Copresence: Using Building Information Models in Virtual Worlds. Ph.D. Thesis, University of Washington, Seattle, WA, USA, 2015.

21. Ahmed, S. A review on using opportunities of augmented reality and virtual reality in construction project management. Organ. Technol. Manag. Constr. 2018, 10, 1839-1852. [CrossRef]

22. Bille, R.; Smith, S.P.; Maund, K.; Brewer, G. Extending building information models into game engines. In Proceedings of the 2014 Conference on Interactive Entertainment, Newcastle, NSW, Australia, 2-3 December 2014; pp. 1-8.

23. Araszkiewicz, K. Digital construction and its role in driving the circular economy. Proc. Creat. Constr. Conf. 2019, $2019,672-681$.

24. Yin, R.K. Case study methods. In APA Handbook of Research Methods in Psychology, Vol. 2. Research Designs: Quantitative, Qualitative, Neuropsychological, and Biological; Cooper, H., Camic, P.M., Long, D.L., Panter, A.T., Rindskopf, D., Sher, K.J., Eds.; American Psychological Association: Washington, DC, USA, 2012; pp. 141-155. [CrossRef]

25. Abdul Nabi, M.; El-adaway, I.H. Modular construction: Determining decision-making factors and future research needs. J. Manag. Eng. 2020, 36, 04020085. [CrossRef]

26. Kirchherr, J.; van Santen, R. Research on the circular economy: A critique of the field. Resour. Conserv. Recycl. 2019, 151, 104480. [CrossRef]

27. Yin, R.K. Discovering the future of the case study. Method in evaluation research. Eval. Pract. 1994, 15, $283-290$.

28. Yin, R.K. The case study method as a tool for doing evaluation. Curr. Sociol. 1992, 40, 121-137. [CrossRef]

29. Sovacool, B.K.; Axsen, J.; Sorrell, S. Promoting novelty, rigor, and style in energy social science: Towards codes of practice for appropriate methods and research design. Energy Res. Soc. Sci. 2018, 45, 12-42. [CrossRef]

30. Baxter, P.; Jack, S. Qualitative case study methodology: Study design and implementation for novice researchers. Qual. Rep. 2008, 13, 544-559. [CrossRef] 
31. Rios, F.C.; Chong, W.K.; Grau, D. Design for Disassembly and Deconstruction-Challenges and Opportunities. Procedia Eng. 2015, 118, 1296-1304. [CrossRef]

32. Akinade, O.; Oyedele, L.; Oyedele, A.; Davila Delgado, J.M.; Bilal, M.; Akanbi, L.; Ajayi, A.; Owolabi, H. Design for deconstruction using a circular economy approach: Barriers and strategies for improvement. Prod. Plan. Control 2020, 31, 829-840. [CrossRef]

33. Eberhardt, L.C.M.; Rønholt, J.; Birkved, M.; Birgisdottir, H. Circular Economy potential within the building stock-Mapping the embodied greenhouse gas emissions of four Danish examples. J. Build. Eng. 2021, 33, 101845. [CrossRef]

34. Jaillon, L.; Poon, C.S. Life cycle design and prefabrication in buildings: A review and case studies in Hong Kong. Autom. Constr. 2014, 39, 195-202. [CrossRef]

35. Tellis, W. Application of a case study methodology. Qual. Rep. 1997, 3, 1-19. [CrossRef]

36. Minunno, R.; O'Grady, T.; Morrison, G.M.; Gruner, R.L.; Colling, M. Strategies for applying the circular economy to prefabricated buildings. Buildings 2018, 8, 125. [CrossRef]

37. Oerter, J.; Suddarth, W.; Morhardt, M.; Gehringer, J.; McGinnis, M.L.; Shockley, J.; Baysa, A. A system architecture and simulation environment for building information modeling in virtual worlds. J. Def. Modeling Simul. 2014, 11, 205-210. [CrossRef]

38. Eastman, C.M.; Eastman, C.; Teicholz, P.; Sacks, R.; Liston, K. BIM Handbook: A Guide to Building Information Modeling for Owners, Managers, Designers, Engineers and Contractors; John Wiley Sons: Hoboken, NJ, USA, 2011.

39. Aye, L.; Ngo, T.; Crawford, R.H.; Gammampila, R.; Mendis, P. Life cycle greenhouse gas emissions and energy analysis of prefabricated reusable building modules. Energy Build. 2012, 47, 159-168. [CrossRef]

40. Fercoq, A.; Lamouri, S.; Carbone, V. Lean/Green integration focused on waste reduction techniques. J. Clean. Prod. 2016, 137, 567-578. [CrossRef]

41. Akanbi, L.A.; Oyedele, L.O.; Akinade, O.O.; Ajayi, A.O.; Davila Delgado, M.; Bilal, M.; Bello, S.A. Salvaging building materials in a circular economy: A BIM-based whole-life performance estimator. Resour. Conserv. Recycl. 2018, 129, 175-186. [CrossRef]

42. Jiménez Rivero, A.; Sathre, R.; García Navarro, J. Life cycle energy and material flow implications of gypsum plasterboard recycling in the European Union. Resour. Conserv. Recycl. 2016, 108, 171-181. [CrossRef]

43. O'Grady, T.; Chong, H.-Y.; Morrison, G.M. A systematic review and meta-analysis of building automation systems. Build. Environ. 2021, 195, 107770. [CrossRef]

44. Rocca, R.; Rosa, P.; Sassanelli, C.; Fumagalli, L.; Terzi, S. Integrating Virtual Reality and Digital Twin in Circular Economy Practices: A Laboratory Application Case. Sustainability 2020, 12, 2286. [CrossRef]

45. Jamei, E.; Mortimer, M.; Seyedmahmoudian, M.; Horan, B.; Stojcevski, A. Investigating the Role of Virtual Reality in Planning for Sustainable Smart Cities. Sustainability 2017, 9, 2006. [CrossRef]

46. Matipa, W.M.; Kelliher, D.; Keane, M. How a quantity surveyor can ease cost management at the design stage using a building product model. Constr. Innov. 2008, 8, 164-181. [CrossRef]

47. Huang, H.-M.; Rauch, U.; Liaw, S.-S. Investigating learners' attitudes toward virtual reality learning environments: Based on a constructivist approach. Comput. Educ. 2010, 55, 1171-1182. [CrossRef]

48. Khan, S.; Rabbani, R.; Thalassinos, I.; Atif, M. Corona Virus Pandemic Paving Ways to Next Generation of Learning and Teaching: Futuristic Cloud Based Educational Model. 2020. Available online: https://www.researchgate.net/publication/34 8730084_Corona_Virus_Pandemic_Paving_Ways_to_Next_Generation_of_Learning_and_Teaching_Futuristic_Cloud_Based_ Educational_Model (accessed on 5 June 2021). 